\title{
Interactive comment on "Evapotranspiration over agroforestry sites in Germany" by Christian Markwitz et al.
}

\section{Christian Markwitz et al.}

christian.markwitz@forst.uni-goettingen.de

Received and published: 14 August 2020

Please find the detailed final response to the referee comment of the Anonymous Referee \#2 in the attached supplement: "Final_response_referee_2_20200814_bg_2020_171.pdf"

Please also note the supplement to this comment:

https://bg.copernicus.org/preprints/bg-2020-171/bg-2020-171-AC2-supplement.pdf 